\title{
Fosphenytoin for the treatment of status epilepticus: an evidence-based assessment of its clinical and economic outcomes
}

\author{
Andrew Thomson
}

Core Medical Publishing, Knutsford, UK

\begin{abstract}
Introduction: Status epilepticus (SE) is a life-threatening condition requiring prompt treatment in the emergency department to control seizures and limit potential neurologic damage. Fosphenytoin is a water-soluble prodrug of phenytoin (an established treatment option for $\mathrm{SE})$ that has been developed to overcome the often severe venous adverse events that can occur following the intravenous administration of phenytoin.
\end{abstract}

Aims: The objective of this article is to review the evidence for the use of fosphenytoin in the treatment of SE.

Evidence review: Fosphenytoin can be infused more rapidly than phenytoin and there is evidence that therapeutic drug levels are achieved at least at a similar rate. Although few studies have been conducted in SE patients, there is evidence that fosphenytoin is at least as effective as phenytoin in terms of response and control of SE. There is also moderate evidence that there are fewer vascular adverse events following intravenous fosphenytoin compared with phenytoin administration when both drugs are infused at the recommended dosage and rate. Evidence from pharmacoeconomic studies indicates that a reduction in the incidence of adverse events and their subsequent management are critical factors for cost-effectiveness with fosphenytoin.

Clinical value: In conclusion, fosphenytoin is a valuable treatment option for the rapid treatment of SE; the risk of venous adverse events is lower than with phenytoin when administered at the recommended rate.

Key words: fosphenytoin, status epilepticus (SE), treatment, evidence, outcomes

\section{Core evidence clinical impact summary for fosphenytoin in status epilepticus}

\begin{tabular}{|c|c|c|}
\hline Outcome measure & Evidence & Implications \\
\hline \multicolumn{3}{|l|}{ Patient-oriented evidence } \\
\hline Reduction in adverse events & Moderate & $\begin{array}{l}\text { Has advantages with improved tolerability compared with intravenous } \\
\text { phenytoin. Faster rate of administration with fosphenytoin compared with phenytoin. } \\
\text { Improved tolerability contributes to cost-effectiveness }\end{array}$ \\
\hline More rapid discharge from emergency department & Limited & Further studies required \\
\hline $\begin{array}{l}\text { Use in children and elderly, and other patient groups } \\
\text { with poor peripheral vascular access }\end{array}$ & Limited & Further studies required \\
\hline \multicolumn{3}{|l|}{ Disease-oriented evidence } \\
\hline More rapid achievement of therapeutic blood levels & Moderate & More rapid infusion rate \\
\hline Seizure control & Moderate & $\begin{array}{l}\text { Effective treatment but more rapid control of status epilepticus seizures with } \\
\text { fosphenytoin has not been demonstrated }\end{array}$ \\
\hline \multicolumn{3}{|l|}{ Economic evidence } \\
\hline Cost-effectiveness & Moderate & Cost-effectiveness reliant upon reduced incidence of adverse events \\
\hline
\end{tabular}




\section{Scope, aims, and objectives}

Status epilepticus (SE) is a serious, life-threatening condition that is often presented at casualty or emergency departments (ED). Phenytoin, a commonly used drug for the treatment of SE, is associated with poor solubility that complicates the use of the intravenous formulation. To overcome this limitation fosphenytoin, a water-soluble prodrug of phenytoin, was introduced in 1996.

The objective of this review is to evaluate the evidence for the use of fosphenytoin in the treatment of SE.

\section{Methods}

The English language medical literature was reviewed for appropriate articles relating to fosphenytoin for the treatment of SE. The following databases were searched on January 5, 2005 using the search terms 'fosphenytoin; status epilepticus AND guidelines' for articles published between January 1990 and December 2004 (inclusive):

\section{- PubMed, www.ncbi.nlm.nih.gov/entrez}

- Database of Abstracts of Reviews of Effectiveness (DARE), NHS Economic Evaluations Database (NHSEED), Health Technology Assessment (HTA), www.york.ac.uk/inst/crd/darehp.htm

\section{- NHS HTA, www.ncchta.org}

- National Guidelines Clearinghouse, www.guideline.gov

- National Institute for Health and Clinical Excellence (NICE), www.nice.org.uk

- Cochrane Database of Systematic Reviews, www.cochrane.org

- Clinical Evidence, www.clinicalevidence.com

A total of 186 articles were identified and animal or in vitro studies were excluded.

Table 1 summarizes the levels of evidence of articles identified from the search strategy (see Editorial Information on inside back cover).

Table 1 | Evidence base included in the review

\begin{tabular}{|lcc|}
\hline Category & \multicolumn{2}{c|}{ Number of records } \\
\cline { 2 - 3 } & Full papers & Abstracts \\
\hline Initial search & 186 & 0 \\
records excluded & 165 & 0 \\
records included & 21 & 0 \\
Additional studies identified & 3 & 3 \\
Level 1 clinical evidence & 0 & 0 \\
Level 2 clinical evidence & 4 & 0 \\
Level $\geq 3$ clinical evidence & 2 & 3 \\
trials other than RCT & 0 & 0 \\
case studies & 3 & 0 \\
Economic evidence & 4 & 0 \\
\hline RCT, randomized controlled trial. & & \\
\hline
\end{tabular}

No systematic reviews were identified for the use of fosphenytoin in the treatment of SE, four papers were of level 2 evidence and there were eight papers and abstracts of level $\geq 3$ evidence (including case studies). In addition, four articles relating to pharmacoeconomic outcomes with fosphenytoin were identified. Six additional articles were identified from a hand search of SE publications to ensure that relevant studies were not overlooked.

\section{Disease overview}

Epilepsy, the presence of unprovoked recurrent seizures, is a serious disorder that affects many patients worldwide. For example, in the USA alone it has a prevalence of approximately 6.6 per 1000 , with about 2.5 million people affected by the condition. Up to $28 \%$ of patients with epilepsy require treatment in EDs annually (ACEP 2004). The economic burden of epilepsy is substantial with annual direct costs of treatment per patient reported to be \$US329-2642 and \$US1531-5065 in the USA and Italy, respectively (Jobst \& Holmes 2004). In addition, the condition also imposes a costly societal burden on individuals, families, and dependents. The medical management of epilepsy is predominantly with the long-term use of oral antiepileptic drugs. However, parenterally administered drugs are necessary for the management of some conditions and emergency situations.

One such epileptic condition is SE, which is a serious medical emergency familiar to EDs, acute medical wards, and intensive care units. Although there is no universally accepted definition of this life-threatening condition it has been defined in a number of incidence studies as 'a clinical seizure lasting more than $30 \mathrm{~min}$, or repeated seizures over a period of more than $30 \mathrm{~min}$ without intervening recovery of consciousness' (Rosenow et al. 2002). Based on earlier animal studies, it has been postulated that the brain can compensate for the increased demands of SE for only $30 \mathrm{~min}$ and that the outcomes for patients (e.g. mortality) with a seizure duration less than $30 \mathrm{~min}$ are significantly better $(P<0.001)$ compared with those over 30 min (DeLorenzo et al. 1999).

In general, SE can be further classified, based on clinical and electrographic criteria, into generalized convulsive status epilepticus (GCSE) and nonconvulsive status epilepticus (NCSE). GCSE is the most common and easily recognized form of SE and is usually diagnosed by observation alone. It is characterized by unconsciousness, tonic-clonic muscle activity, urinary incontinence, and tongue biting. However, with prolonged seizure activity, these clinical characteristics become less apparent. The fundamental pathophysiology of SE involves a failure of inherent cellular mechanisms to prevent sustained seizure activity (Scott et al. 1998). The failure may be due to either ineffective inhibitory or excessive excitatory processes, although it is likely that several factors are involved in this poorly understood process (Lowenstein \& Alldredge 1998).

NCSE may account for $30-40 \%$ of all cases of SE, an incidence of approximately five to nine per 100000 in the general population. It is characterized by continuous or near continuous focalized or generalized seizure activity detected by electroencephalogram (EEG) for at least 30 min without physical convulsions. NCSE carries an increased risk for evolving into refractory SE and is associated with a three-fold increase in long-term mortality compared with the 
Table 2 | Etiologic factors of generalized convulsive status epilepticus

Subtherapeutic antiepileptic drug levels

Cerebral trauma

Infection, central nervous system or general

Cerebrovascular accident

Metabolic disturbance (e.g. electrolyte imbalance)

Drug overdose

Hypoxia

History of epilepsy

Tumor

Alcohol abuse

healthy population. The overall mortality in SE has been reported to be approximately $30 \%$ (estimates range from 2 to $61 \%$ ), whereas NCSE-associated mortality appears to be higher, approximately $50 \%$ (estimates range from 33 to 57\%) (Rüeegg \& Dichter 2003).

There are about 102 000-152 000 new cases of SE in the USA per year and around 22 000-42 000 deaths annually associated with the condition (DeLorenzo et al. 1995). At approximately $22 \%$, this mortality rate is within the overall SE mortality range reported by Rüeegg and Dichter (2003). Data from other countries also show that $\mathrm{SE}$ is common. For example, the minimum estimated incidence is approximately 20 per 100000 in Switzerland and Germany (Rosenow et al. 2002), while in India, SE accounted for $11 \%$ of neurologic admissions to intensive care units (Swaminathan et al. 1998). It is interesting to note that in studies in the USA, the incidence of SE in the black population is three times higher than in Caucasians (reviewed in Rosenow et al. 2002). In addition, the incidence is higher in males and is age-related, with the highest incidence in children and the elderly. As the relative proportion of the aging population is increasing globally, it is expected that there will be a corresponding increase in the incidence of SE (Rosenow et al. 2002). About a third of all instances of SE occur in patients with a history of epilepsy or febrile seizures, one-third in patients whose first sign of epilepsy is an episode of SE, and the remaining third result from encephalopathic insult to the brain (Treiman 1999). Other causes of SE include trauma, hypoxia, stroke, infection, and drug withdrawal (Table 2).

Patients with a first episode of SE are at considerable risk for both future episodes and the development of chronic epilepsy (Lowenstein \& Alldredge 1998). Although outcome is usually worse in patients with SE of long duration and those with physiologic disturbances, it is the etiology of SE (Table 2) that has the greatest influence on outcome. Mortality is highest in elderly patients or when SE is secondary to an acute event (e.g. acute stroke, central nervous system infection, head trauma, metabolic disturbances, drug toxicity, and hypoxia). In contrast, SE secondary to previous strokes, withdrawal from alcohol or anticonvulsant drugs, tumours, or epilepsy has a more favorable prognosis (Manno 2003). To date, one study has looked at a long-term outcome, 10-year mortality after a first episode of SE that received medical attention (Logroscino et al. 2002). In this study $40 \%$ of patients who survived the first 30 days after an incident episode of SE died within the next 10 years: three times the mortality rate compared with the general population over the same time period. This study indicated that significant risk factors for long-term mortality (prolonged SE duration, myoclonic SE, and advanced age) replicated those factors that influence short-term mortality (Towne et al. 1994).

Recently, the inpatient costs associated with SE in the USA alone have been estimated to range from $\$$ US3.8-7 billion per year (Sirven \& Waterhouse 2003).

\section{Current therapy options for status epilepticus}

Because of the emergency nature of the condition, the aim of SE treatment is the prompt termination of seizure activity and subsequent prevention of seizure recurrence. Once the patient is diagnosed with SE, rapid administration of drug therapy is necessary to both reduce the potential for neurologic morbidity and increase the probability of response to therapy; SE of long duration is less responsive to drug therapy compared with SE of shorter duration (Lowenstein \& Alldredge 1998).

Initial drug treatment of SE usually involves a parenterally administered benzodiazepine (lorazepam or diazepam) or a hydantoin (Lowenstein \& Alldredge 1998; Holmes \& Riviello 1999; Manno 2003). Most cases of SE respond to these initial treatment options. However, SE that does not respond to these therapies is considered to be refractory. Agents used in this situation include phenobarbital or pentobarbital, propofol, and midazolam. Current treatments for SE are shown in Table 3.

There have been a number of attempts to identify optimal treatment regimens for SE. Treatment protocols shorten the time needed to control seizures. Typically they include the sequential administration of benzodiazepines, phenytoin, and phenobarbital, and finally pentobarbital-induced coma for patients with refractory seizures (Manno 2003). However, it has been suggested that actual drug choice may be less important than the development of a protocol itself (Shorvon 2001), but this reflects the importance of achieving a rapid response.

The ideal drug for the treatment of SE should be easy to administer, achieve immediate and long-lasting antiseizure activity, and also be free from serious respiratory depression, cardiovascular and sedative effects, and local irritation at the injection site. However, all the currently available therapies used to treat SE fail this ideal in some respect. Adverse events with the benzodiazepines include respiratory suppression, hypotension, and sedation. Similarly, although the hydantoins lack sedative effects they have also been associated with hypotension. In addition, local venous irritation, pain, and phlebitis can also occur with intravenous phenytoin. Phenobarbital, which is sedative, is often used following failure to control SE with a benzodiazepine or hydantoin; however, it too is associated with systemic hypotension. Finally, propofol, another option if previous therapy has failed, may lead to instances of severe metabolic acidosis particularly in children with metabolic enzymatic defects (Manno 2003). Despite the potential adverse events associated with these agents, they still have a place in the therapeutic management of SE.

Even with the development of medication protocols, treatment may still vary among physicians. A recent survey of neurologists (mainly 
Table 3 | Summary of antiepileptic drugs used for the treatment of status epilepticus (adapted from Manno 2003; Sirven \& Waterhouse 2003)

\begin{tabular}{|c|c|c|c|}
\hline Drug (route) & Potential AEs & Advantages & Disadvantages \\
\hline \multicolumn{4}{|l|}{ Benzodiazepines } \\
\hline \multirow{3}{*}{$\begin{array}{l}\text { Diazepam } \\
\text { (iv, rectal) }\end{array}$} & \multirow{3}{*}{$\begin{array}{l}\text { Respiratory depression, hypotension, } \\
\text { decreased level of consciousness }\end{array}$} & Most rapidly acting (10-20 s) & Short duration of action (<20 min) \\
\hline & & Stable in liquid form at room temperature & Second-line drug required \\
\hline & & $\begin{array}{l}\text { Rectal administration commonly used for } \\
\text { children }\end{array}$ & \\
\hline \multirow{2}{*}{$\begin{array}{l}\text { Lorazepam } \\
\text { (iv) }\end{array}$} & \multirow{2}{*}{$\begin{array}{l}\text { Respiratory depression, hypotension, } \\
\text { decreased level of consciousness }\end{array}$} & Long duration of action (4-6 h) & Refrigerated storage \\
\hline & & May be least respiratory depressant in class & $\begin{array}{l}\text { Delay in brain uptake (2 min to maximal } \\
\text { effect) }\end{array}$ \\
\hline \multirow{3}{*}{$\begin{array}{l}\text { Midazolam } \\
\text { (iv, im) }\end{array}$} & \multirow{3}{*}{$\begin{array}{l}\text { Respiratory depression, hypotension, } \\
\text { decreased level of consciousness }\end{array}$} & Rapid acting (<1 min) & Short duration of action \\
\hline & & & Second-line drug required \\
\hline & & & Minimal CV effects \\
\hline \multicolumn{4}{|l|}{ Hydantoins } \\
\hline \multirow{3}{*}{$\begin{array}{l}\text { Fosphenytoin } \\
\text { (iv) }\end{array}$} & \multirow[t]{3}{*}{ Hypotension, cardiac arrhythmias, pruritus } & Potentially fewer AEs & CV monitoring \\
\hline & & Faster infusion rate than phenytoin & AEs \\
\hline & & & High acquisition cost \\
\hline \multirow[t]{2}{*}{ Phenytoin (iv) } & \multirow{2}{*}{$\begin{array}{l}\text { Hypotension, QT interval prolongation, } \\
\text { PGS, venous irritation, phlebitis }\end{array}$} & Low cost & $\mathrm{AE}$ profile (infusion rate, $\mathrm{CV}$ monitoring) \\
\hline & & Effective in longer-term seizure recurrence & \\
\hline \multicolumn{4}{|l|}{ Barbiturates } \\
\hline \multirow[t]{2}{*}{ Phenobarbital (iv) } & \multirow{2}{*}{$\begin{array}{l}\text { Hypotension, respiratory depression, } \\
\text { decreased level of consciousness }\end{array}$} & Long acting & Long half-life \\
\hline & & & $\begin{array}{l}\text { More hypoventilation, more hypotension } \\
\text { than benzodiazepines or phenytoin }\end{array}$ \\
\hline Pentobarbital (iv) & $\begin{array}{l}\text { Hypotension, respiratory depression, } \\
\text { decreased level of consciousness }\end{array}$ & Shorter half-life than phenobarbital & $\begin{array}{l}\text { More hypoventilation, more hypotension } \\
\text { than benzodiazepines or phenytoin }\end{array}$ \\
\hline \multicolumn{4}{|c|}{ General anesthetic } \\
\hline \multirow[t]{2}{*}{ Propofol (iv) } & \multirow{2}{*}{$\begin{array}{l}\text { Hypotension, respiratory depression, } \\
\text { acidosis, lipemia }\end{array}$} & Rapid onset of action & AE profile in children \\
\hline & & Rapid recovery & \\
\hline
\end{tabular}

in medical schools and private practice) evaluated current treatment preferences for GCSE. Of the 106 respondents 76\% initially treated patients with intravenous lorazepam, while 95\% would use phenytoin or fosphenytoin if seizures continued for 10 min following initial benzodiazepine treatment (Claassen et al. 2003). Fosphenytoin was more popular with respondents than phenytoin (65 versus $31 \%$, respectively). Phenytoin and fosphenytoin have also been recommended for second-line treatment in general guidelines for treating GCSE (Lowenstein \& Alldredge 1998; Appleton et al. 2000; Rosenow et al. 2002).

Phenytoin can be used as an initial treatment for cessation of seizure activity, for maintaining a prolonged antiseizure effect following effective treatment with a benzodiazepine, or when benzodiazepines are ineffective. Its mode of action is to limit the repetitive firing of action potentials by slowing the rate of recovery of voltage-activated sodium channels. Parenteral sodium phenytoin is formulated with $40 \%$ propylene glycol and $10 \%$ ethanol in water for injection adjusted to $\mathrm{pH} 12$ with sodium hydroxide. The recommended starting dose for intravenous phenytoin is $20 \mathrm{mg} / \mathrm{kg}$ (via a large vein) given at a maximal rate of $50 \mathrm{mg} / \mathrm{min}$ to achieve therapeutic serum concentrations of $10-20 \mathrm{mg} / \mathrm{L}$. Therefore it would take nearly 30 min to give the required dose to a patient weighing $70 \mathrm{~kg}$, which is undesirable given that the aim of SE treatment is the prompt termination of seizure activity. The recommended dose for children is $18 \mathrm{mg} / \mathrm{kg}$ infused over $20 \mathrm{~min}$ (maximum infusion rate $1 \mathrm{mg} / \mathrm{kg}$ per $\mathrm{min}$ ), which is similarly inappropriate (Appleton et al. 2000). In addition, adverse effects following use of intravenous phenytoin in SE can be common and are cardiovascular-related: hypotension, QT prolongation, and cardiac dysrhythmias may occur and these are direct effects of the active ingredient and excipients, plus local venous irritation and pain may occur. Propylene glycol in the formulation contributes to the hypotension and cardiac arrhythmias observed with the rapid infusion of phenytoin (Fischer et al. 2003).

One of the most poorly understood and potentially serious local complications of intravenous phenytoin administration is the purple glove syndrome, which is characterized by progressive limb edema, discoloration, and pain. In the only reported systematic study of this syndrome, the incidence of purple glove syndrome was $5.9 \%$ (nine of 152) in patients receiving intravenous phenytoin (O'Brien et al. 1998). Thus, while the efficacy of phenytoin for the treatment of acute seizures and SE is well established (Treiman et al. 1998), its 
parenteral formulation, specifically excipients and high alkalinity, limits its rate of administration and influences its tolerability.

Fosphenytoin is a water-soluble prodrug of phenytoin and is converted to the active compound by nonspecific phosphatases in the blood (reviewed in Browne 1997). The dose of fosphenytoin is expressed as phenytoin equivalence ( $75 \mathrm{mg}$ fosphenytoin is labelled as $50 \mathrm{mg}$ phenytoin equivalent). Unlike phenytoin, fosphenytoin is not formulated with propylene glycol and its $\mathrm{pH}$ of 8.6-9 means that it may be infused more rapidly, up to $150 \mathrm{mg}$ phenytoin equivalent per minute. Thus, a starting dose of $20 \mathrm{mg} / \mathrm{kg}$ intravenous phenytoin equivalent may be given to a $70-\mathrm{kg}$ patient in just under $10 \mathrm{~min}$. Potential practical benefits with fosphenytoin include more rapid achievement of therapeutic blood levels and decreased risk and incidence of serious adverse effects compared with phenytoin. In addition, fosphenytoin may be preferable for patients with difficult vascular access (e.g. children, the elderly, and intravenous drug abusers). Although intramuscular administration of fosphenytoin may be used as a loading dose strategy, this route is not recommended for treating SE because of the delay in achieving therapeutic plasma concentrations of phenytoin (Fierro et al. 1996).

\section{Clinical evidence for the role of fosphenytoin in the treatment of SE}

Short-term outcomes are commonly examined in SE clinical trials. This is due to their importance in the longer-term prognosis following an episode of SE and treatment with antiepileptic drugs. Examples of short-term outcomes include achievement of therapeutic drug levels, time to seizure recurrence, failure of firstline therapy, and time to discharge from the ED. There are few studies of patients with new-onset seizures in the ED and most reports use abnormal laboratory or diagnostic tests (e.g. EEG) as the outcome measure (ACEP 2004).

The long-term prognosis for SE is improved if seizures are controlled within 30 min of onset. Thus, rapid drug control of seizures is an advantage and a component of this is the timely achievement of therapeutic drug levels. Fosphenytoin should have an advantage over phenytoin in this respect, as it can be infused more rapidly. Clinical evidence is available that compares the achievement of therapeutic drug levels, seizure control, and tolerability (particularly vascular reactions) with fosphenytoin and phenytoin.

\section{Achievement of therapeutic drug levels}

There is some good evidence supporting the achievement of therapeutic levels of phenytoin with intravenous fosphenytoin (Table 4). Most studies evaluating the pharmacokinetics of fosphenytoin and phenytoin use 'achievement of a therapeutic serum concentration of phenytoin' as the primary outcome measure. However, 'therapeutic' phenytoin serum level may be a misleading term, as some patients can be seizure-free at phenytoin levels $<10 \mathrm{mg} / \mathrm{L}$ and yet others require serum levels $>20 \mathrm{mg} / \mathrm{L}$ for seizure control (ACEP 2004). Studies evaluated here have included both SE and non-SE patient populations, as the achievement of therapeutic drug levels is independent of the presence of SE.

In a study in children with malaria and SE (in endemic tropical regions falciparum malaria is a common cause of convulsions in children), maximum peak plasma phenytoin concentrations were achieved more rapidly with intravenous fosphenytoin compared with intravenous phenytoin (0.08 vs 0.37 h) (Ogutu et al. 2003).

Two abstracts have reported the achievement of therapeutic levels of phenytoin with fosphenytoin administration in single-arm, openlabel studies in patients with SE. Total phenytoin concentrations of $\geq 10 \mathrm{mg} / \mathrm{L}$ and free phenytoin concentrations of $\geq 1 \mathrm{mg} / \mathrm{L}$ were achieved within 10-20 min of commencing the infusion of fosphenytoin in 40 patients with SE; mean infusion duration $11 \mathrm{~min}$ (Allen et al. 1995). In another study of 39 patients (22 with SE and 17 non-SE patients), treated with intravenous fosphenytoin (10-20 mg/kg phenytoin equivalent), pharmacokinetic data were collected from 20 patients (Runge et al. 1995). Therapeutic levels of free phenytoin $(0.9-1.8 \mathrm{mg} / \mathrm{mL}$ [sic]) were achieved within $10 \mathrm{~min}$ in all 20 patients. However, it should be noted that the target infusion rate for fosphenytoin was $50-100 \mathrm{mg} / \mathrm{min}$ for non-SE patients and $100-150 \mathrm{mg} / \mathrm{min}$ for SE patients and it is unclear what proportion of participants from these two groups provided the pharmacokinetic data.

Although the maximal rate of intravenous administration is three times faster with fosphenytoin than with phenytoin, there is only limited evidence that phenytoin levels are actually achieved faster with fosphenytoin. For example, in a small, randomized controlled study, phenytoin $(n=14)$ and fosphenytoin $(n=15)$ were administered

Table 4 | Summary of outcome evidence for intravenous fosphenytoin: achievement of therapeutic drug levels

\begin{tabular}{|c|c|c|c|c|}
\hline $\begin{array}{l}\text { Level of } \\
\text { evidence }\end{array}$ & Outcomes & Comparators & Study population & $\begin{array}{l}\text { Study } \\
\text { reference }\end{array}$ \\
\hline 2 & $\begin{array}{l}\text { Mean times to achieve therapeutic drug concentrations were } \\
0.24 \mathrm{~h} \text { (iv PT) and } 0.21 \mathrm{~h} \text { (iv FOS). Both iv groups were } \\
\text { significantly shorter compared with oral PT ( } 5.62 \mathrm{~h}, P<0.001 \text { ) }\end{array}$ & $\begin{array}{l}\text { FOS (iv) vs. PT } \\
\text { (iv or oral) }\end{array}$ & $\begin{array}{l}n=45 \text { patients with subtherapeutic PT levels } \\
\text { within } 48 \text { h of a seizure (oral PT } n=16 \text {; iv PT } \\
n=14 \text {; iv FOS } n=15 \text { ) }\end{array}$ & $\begin{array}{l}\text { Swadron et al. } \\
2004\end{array}$ \\
\hline 3 & $\begin{array}{l}\text { Mean time to peak PT concentrations following loading dose } \\
\text { were } 0.08 \mathrm{~h} \text { (iv FOS), } 0.37 \mathrm{~h} \text { (iv PT), and } 0.38 \mathrm{~h} \text { (im FOS) }\end{array}$ & $\begin{array}{l}\text { FOS (iv or im) } \\
\text { vs PT (iv) }\end{array}$ & $\begin{array}{l}n=38 \text { children with SE and severe falciparum } \\
\text { malaria (iv PT } n=11 \text {; iv FOS } n=16 \text {; im FOS } n=11 \text { ) }\end{array}$ & $\begin{array}{l}\text { Ogutu et al. } \\
2003\end{array}$ \\
\hline 3 & $\begin{array}{l}\text { Total and free phenytoin concentrations of } \geq 10 \mathrm{mg} / \mathrm{L} \text { and } \geq 1 \mathrm{mg} / \mathrm{L} \\
\text { respectively, achieved within } 10-20 \mathrm{~min} \text { of starting infusion }\end{array}$ & FOS (iv) & $\mathrm{n}=40$ patients with $\mathrm{SE}$ & $\begin{array}{l}\text { Allen et al. } \\
1995\end{array}$ \\
\hline 3 & $\begin{array}{l}\text { Therapeutic PT levels achieved within } 10 \text { min of FOS infusion } \\
\text { of all }(n=20) \text { patients with PK data }\end{array}$ & FOS (iv) & $\mathrm{n}=39$ patients following benzodiazepine therapy & $\begin{array}{l}\text { Runge et al. } \\
1995\end{array}$ \\
\hline
\end{tabular}


Table 5 | Summary of outcome evidence for intravenous fosphenytoin: seizure control in status epilepticus patients

\begin{tabular}{|c|c|c|c|c|}
\hline $\begin{array}{l}\text { Level of } \\
\text { evidence }\end{array}$ & Outcomes & Comparators & Study population & $\begin{array}{l}\text { Study } \\
\text { reference }\end{array}$ \\
\hline 2 & $\begin{array}{l}\text { For nine patients with SE, seizures ceased after } 31.8 \mathrm{~min} \\
\text { with PT vs } 49.5 \mathrm{~min} \text { with FOS }(P=0.8)\end{array}$ & $\begin{array}{l}\text { FOS (iv or im) } \\
\text { vs PT (iv) }\end{array}$ & $\mathrm{n}=9$ with $\mathrm{SE}$ from 256 patients & $\begin{array}{l}\text { Coplin et al. } \\
2002\end{array}$ \\
\hline 3 & SE terminated within $30 \mathrm{~min}$ of FOS infusion in $85 \%$ of patients & FOS (iv) & $\mathrm{n}=40$ patients with $\mathrm{SE}$ & $\begin{array}{l}\text { Allen et al. } \\
1995\end{array}$ \\
\hline 3 & Seizures controlled in $97 \%$ of patients & FOS (iv) & $\mathrm{n}=39$ patients following benzodiazepine therapy & $\begin{array}{l}\text { Runge et al. } \\
1995\end{array}$ \\
\hline 3 & $\begin{array}{l}\text { SE controlled in } 36 \% \text { (iv PT), } 44 \% \text { (iv FOS), and } 64 \% \\
\text { (im FOS) of patients }\end{array}$ & $\begin{array}{l}\text { FOS (iv or im) } \\
\text { vs PT (iv) }\end{array}$ & $\begin{array}{l}n=38 \text { children with SE and severe falciparum } \\
\text { malaria (iv PT } n=11 \text {; iv FOS } n=16 \text {; im FOS } n=11 \text { ) }\end{array}$ & $\begin{array}{l}\text { Ogutu et al. } \\
2003\end{array}$ \\
\hline
\end{tabular}

at the recommended initial rates of 50 and $150 \mathrm{mg} / \mathrm{min}$, respectively, and therapeutic phenytoin concentrations were reached at a mean of 0.24 and $0.21 \mathrm{~h}$, respectively (Swadron et al. 2004). One possible reason for the difference is the delay (half-life 8-15 min) in the conversion of fosphenytoin to phenytoin by phosphatases in blood and other tissues (Browne 1997). Plasma phenytoin concentrations were measured using an immunoassay in this study (Swadron et al. 2004). This method may overestimate actual phenytoin plasma concentrations by 1.2-6-fold when fosphenytoin is present (Fischer et al. 2003). The other studies used more specific high-performance liquid chromatography assays where interference does not occur (Fischer et al. 2003).

\section{Seizure control in SE patients}

The evidence suggests that fosphenytoin is as effective as phenytoin in speed of seizure resolution and in the proportion of patients responding to treatment (Table 5).

When considering the use of intravenous fosphenytoin specifically for the treatment of SE four studies categorized at level 3 evidence or higher were identified. Two of these were single-arm design (Allen et al. 1995; Runge et al. 1995), while the third was a study in children with SE plus the added complication of falciparum malaria (Ogutu et al. 2003). Finally, although the fourth study involved a large number of patients only nine were diagnosed with SE (Coplin et al. 2002).

In the study in children with malaria plus SE, the defined clinical outcomes were abolition of seizures within $30 \mathrm{~min}$ of commencing drug therapy, or SE characterized by recurrent convulsions of short duration, which were considered controlled if there were no convulsions within $12 \mathrm{~h}$ of drug therapy (Ogutu et al. 2003). SE was controlled in seven of 16 children following intravenous fosphenytoin and in four of 11 following intravenous phenytoin.

In an abstract of a single-arm, open-label study in SE patients, seizure control was achieved in $85 \%$ (37 of 40) patients within $30 \mathrm{~min}$ of receiving intravenous fosphenytoin (mean infusion duration $11 \mathrm{~min}$ ) (Allen et al. 1995). In the second single-arm study 39 patients (SE $\mathrm{n}=22$, epilepsy patients $\mathrm{n}=17$ ) were treated with intravenous fosphenytoin. No seizures were noted in 38 (97\%) of these patients after intravenous fosphenytoin. The mean dose in SE patients was $16.1 \mathrm{mg} / \mathrm{kg}$ (range $9.6-22 \mathrm{mg} / \mathrm{kg}$ ) administered at a mean infusion rate of $134.4 \mathrm{mg} / \mathrm{min}$ (range $54-183 \mathrm{mg} / \mathrm{min}$ ) (Runge et al. 1995).
In a large, open-label randomized study, 256 ED patients were prescribed 279 parenteral doses of phenytoin or fosphenytoin (phenytoin $n=77$, fosphenytoin $n=202$ ). Time to seizure cessation in the nine patients diagnosed with SE was not significantly different with fosphenytoin compared with phenytoin (Coplin et al. 2002)

\section{Tolerability and adverse events}

There is some good evidence supporting the improved tolerability of fosphenytoin compared with phenytoin (Table 6). Some studies with non-SE patient populations have been used in this evaluation, as tolerability of fosphenytoin does not depend on the presence of SE.

In a study of 29 non-SE patients, phenytoin and fosphenytoin were administered intravenously at the recommended initial rates of 50 and $150 \mathrm{mg} / \mathrm{min}$, respectively, and a total of 27 and 32 adverse events were recorded in the respective groups $(P=0.55)$. However, pain and phlebitis were experienced more frequently following phenytoin compared with fosphenytoin (11 vs $3, P<0.001)$. The occurrence of perineal pruritus was exclusively associated with fosphenytoin (12 vs $0, P<0.0001$ ), requiring a reduction in infusion rate in some patients (Swadron et al. 2004). Perineal pruritus is reversible and has previously been noted to occur with high infusion rates of fosphenytoin (Sirven \& Waterhouse 2003).

There is further evidence to support improved tolerability with fosphenytoin. In a randomized, double-blind, crossover study, 12 healthy volunteers received a 30-min infusion of $250 \mathrm{mg}$ phenytoin, or fosphenytoin equivalent, to evaluate venous irritation. Phenytoin was associated with a significantly higher level of infusion site pain (all subjects, $P<0.05$ ) and phlebitis (eight subjects $P<0.05$ ); cording occurred in six subjects. Erythema and tenderness were prominent at the conclusion of the phenytoin infusion and again on examination $24 \mathrm{~h}$ later. In contrast, fosphenytoin was associated with mild pain in only two subjects, and phlebitis in one; no instances of erythema or cording were noted (Jamerson et al. 1994). In this early study, both drugs were infused at the same rate; however, it is now recognized that fosphenytoin may be administered at three times the rate of phenytoin.

Venous-related adverse events were also noted more often with intravenous loading doses of phenytoin compared with fosphenytoin in a randomized, double-blind study in 23 non-SE 
Table 6 | Summary of outcome evidence for intravenous fosphenytoin: adverse events

\begin{tabular}{|c|c|c|c|c|}
\hline $\begin{array}{l}\text { Level of } \\
\text { evidence }\end{array}$ & Outcomes & Comparators & Study population & $\begin{array}{l}\text { Study } \\
\text { reference }\end{array}$ \\
\hline 2 & $\begin{array}{l}\text { Lower incidence of infusion site irritation with iv FOS }(6 \%) \text { compared } \\
\text { with iv PT }(25 \%, P<0.05)\end{array}$ & $\begin{array}{l}\text { FOS (iv or im) } \\
\text { vs PT (iv) }\end{array}$ & $\begin{array}{l}n=116 \text { neurosurgical patients }(n=88 \text { iv FOS; } \\
n=28 \text { iv } P T)\end{array}$ & $\begin{array}{l}\text { Boucher et al. } \\
1996\end{array}$ \\
\hline 2 & $\begin{array}{l}\text { Total of } 17 \text { (oral PT), } 27 \text { (iv PT), and } 32 \text { (iv FOS) AEs } \\
\text { Significantly fewer AEs with oral PT vs both iv groups, } P \leq 0.02\end{array}$ & $\begin{array}{l}\text { FOS (iv) vs PT } \\
\text { (iv or oral) }\end{array}$ & $\begin{array}{l}n=45 \text { patients (oral PT } n=16 \text {; iv PT } n=14 \text {; } \\
\text { iv FOS } n=15 \text { ) }\end{array}$ & $\begin{array}{l}\text { Swadron et al. } \\
2004\end{array}$ \\
\hline 2 & $\begin{array}{l}\text { Venous irritation (pain) reported by } 12 \text { subjects receiving PT vs two } \\
\text { subjects receiving FOS. Phlebitis, eight cases with PT vs one case } \\
\text { with FOS }(P<0.05) \text {; and six cases of cording vs } 0 \text { instances with FOS }\end{array}$ & $\begin{array}{l}\text { FOS (iv) vs PT } \\
\text { (iv) }\end{array}$ & $\mathrm{n}=12$ healthy volunteers (crossover study) & $\begin{array}{l}\text { Jamerson et } \\
\text { al. } 1994\end{array}$ \\
\hline 2 & $\begin{array}{l}\text { Infusion rate altered because of an AE with } 6.5 \% \text { PT patients vs } \\
6.4 \% \text { FOS patients }(P=1.0) \\
\text { AE frequency } 9.1 \% \text { with PT vs } 15.8 \% \text { with FOS }(P=0.3)\end{array}$ & $\begin{array}{l}\text { FOS (iv or im) } \\
\text { vs PT (iv) }\end{array}$ & $\begin{array}{l}n=256 \text { ED patients ( } 279 \text { parenteral doses } \\
\text { of a PT equivalent; FOS } n=202 ; \text { PT } n=77 \text { ) }\end{array}$ & $\begin{array}{l}\text { Coplin et al. } \\
2002\end{array}$ \\
\hline 3 & $\begin{array}{l}\text { AEs arising from loading doses included adjustment of infusion rate in } \\
67 \% \text { PT vs } 12 \% \text { FOS recipients }(P<0.05) \text {. Injection site pain occurred } \\
\text { in } 83 \% \text { PT vs } 0 \% \text { FOS recipients }\end{array}$ & $\begin{array}{l}\text { FOS (iv) vs PT } \\
\text { (iv) }\end{array}$ & $\mathrm{n}=17$ FOS, $\mathrm{n}=6$ PT & $\begin{array}{l}\text { Andrews et al. } \\
1994\end{array}$ \\
\hline 3 & $\begin{array}{l}\text { Initial iv site maintained in a higher proportion of FOS recipients }(58 \%) \\
\text { vs PT recipients ( } 38 \%) \\
\text { Fewer site changes (due to irritation) with FOS (11\%) vs PT ( } 42 \%)\end{array}$ & $\begin{array}{l}\text { FOS (iv) vs PT } \\
\text { (iv) }\end{array}$ & $\begin{array}{l}n=208(n=167 \text { FOS; } n=41 \text { PT). Review of } \\
3 \text { studies }\end{array}$ & $\begin{array}{l}\text { Baron et al. } \\
1995\end{array}$ \\
\hline 3 & $\begin{array}{l}\text { Nurse-reported venous irritation in } 62.3-74 \% \text { of PT recipients vs } 0 \% \\
\text { with FOS }\end{array}$ & $\begin{array}{l}\text { FOS (iv or im) } \\
\text { vs PT (iv) }\end{array}$ & $\begin{array}{l}\mathrm{n}=33 \text { nurses from critical care, ED and } \\
\text { neurology services }\end{array}$ & $\begin{array}{l}\text { Armstrong et } \\
\text { al. } 1999\end{array}$ \\
\hline
\end{tabular}

patients (Andrews et al. 1994). Pain and phlebitis occurred in 83\% of phenytoin recipients compared with none in those treated with fosphenytoin. Infusion rate adjustment, as a result of adverse events, was required in significantly more phenytoin recipients compared with those receiving fosphenytoin (67 vs $12 \% ; P<0.05$ ). Although there were complaints of transient, generalized itching and warmth in $53 \%$ of the fosphenytoin group, as noted above, infusion rate adjustment was only necessary in a minority of the group.

In another double-blind, randomized study, 88 patients received intravenous fosphenytoin and 28 patients received intravenous phenytoin to achieve serum phenytoin concentrations of 10-20 mg/L. This was followed by maintenance doses for up to 14 days. The frequency of mild irritation was significantly lower following fosphenytoin compared with phenytoin (6 vs $25 \%$, $P<0.05)$ and reductions in infusion rates were required in 17 and $36 \%$ of recipients, respectively (Boucher et al. 1996).

Infusion site changes were also highlighted in a review of 208 patients (with epilepsy, neurosurgical or with SE) participating in three studies. A larger proportion of fosphenytoin recipients maintained their original intravenous site (58 vs 38\%), and change in infusion site was less common with fosphenytoin compared with phenytoin (11 vs 42\%) (Baron et al. 1995).

A questionnaire was used to capture effectiveness data from 33 nurses in critical care, emergency, and neurology services in a metropolitan area in the USA. In this study, venous irritation occurred in a mean of $62.3 \pm 43.4 \%$ of patients receiving phenytoin loading doses and $74 \pm 32.9 \%$ receiving maintenance doses. Each local reaction required $34.7 \pm 9.3 \mathrm{~min}$ of nursing time for management. In contrast, adverse events associated with fosphenytoin were uncommon $(0.3 \pm 1 \%)$ and there were no nursereported local reactions following intravenous (or intramuscular) administration (Armstrong et al. 1999) (see also 'Resource utilization' below).

One study, however, reported that fosphenytoin and phenytoin are associated with a similar incidence of adverse events. In this large, open-label randomized study of 256 ED patients who were prescribed 279 parenteral doses of phenytoin or fosphenytoin (phenytoin $n=77$, fosphenytoin $n=202$ ), the incidence of adverse events was similar between the two treatment groups (odds ratio 0.7 , confidence interval $0.3-1.4 ; P=0.3)$. It is worth noting that, although the time taken to administer fosphenytoin (13 min, range 1-75 min) was significantly shorter than with phenytoin (45 min, range 15-165 min, $P<0.001$ ), the protocol specified the rate of phenytoin administration as $20 \mathrm{mg} / \mathrm{min}$ (vs maximum recommended rate of $50 \mathrm{mg} / \mathrm{min}$ ). Thus, the reduced rate of administration with phenytoin is the most likely reason for the lower incidence of adverse events, since it would avoid serious adverse events, including drug extravasation and hypotension. In addition, fosphenytoin was also administered at a reduced rate of $100 \mathrm{mg}$ phenytoin equivalent per minute (Coplin et al. 2002). Since only nine patients of the 256 patients had SE, rapid seizure resolution was not the prime objective of the study. Hence, the low rates of infusion are not necessarily appropriate for the treatment of SE.

\section{Economic evidence}

When compared strictly on acquisition cost, fosphenytoin is more expensive than phenytoin. It has been reported that the difference in cost with fosphenytoin is 10-20 times greater when compared with generic versions of intravenous phenytoin (Jobst \& Holmes 2004). To get an overall evaluation of the economic impact of using fosphenytoin to treat SE, the costs associated with adverse events, rapid seizure control and discharge from ED, and long-term sequelae need to be considered. However, at present there is no published 
evidence specifically comparing fosphenytoin with phenytoin in patients with SE so any extrapolation of results conducted in other patient groups must therefore be treated with caution.

Since fosphenytoin and phenytoin are bioequivalent and therefore of equivalent efficacy, it is unlikely that there will be any difference in patient outcome costs in terms of the proportion achieving seizure reduction. Therefore, differences in drug-related patient outcome costs of SE treatment are likely to include the failure of the patient to respond to the treatment, the period spent in the ED (time to discharge), and the management of drug-related adverse events. As fosphenytoin can be administered more rapidly, and it is at least as well tolerated as phenytoin, cost differences with these latter outcomes may, in theory, favour fosphenytoin.

Four pharmacoeconomic analyses comparing intravenous fosphenytoin with intravenous phenytoin in the ED setting have been conducted in the USA (Table 7). The study by Marchetti et al. suggested a cost saving of $\$$ US386.89 with fosphenytoin relative to phenytoin (Marchetti et al. 1996). However, this study used clinical results from a multicenter trial conducted in one state and financial data from a different institution in California, which would probably differ with both other states and other countries. In addition, calculation of the cost of emergency room treatment relied upon average fixed and variable costs, whereas only variable or marginal care costs are recommended for this type of analysis (Weinstein et al. 1996). However, more pertinent to this review, patients with SE were actually excluded from the analysis.

In the analysis performed by Rudis et al. (2004), the most costeffective loading method in most settings was phenytoin administered orally. The time taken to achieve therapeutic blood levels with this route of administration precludes its use as a treatment for SE. A more relevant comparison in this study showed that the incremental cost-effectiveness ratio (i.e. the difference in costs divided by the difference in health outcomes) was $\$$ US387.27/h of ED time saved for intravenous fosphenytoin versus intravenous phenytoin (Table 7) (Rudis et al. 2004). In this study, drug administration was carried out at a General Clinical Research Center under conditions which do not accurately represent acute treatment. In addition, SE patients were excluded (Swadron et al. 2004).

A study using cost-minimization analysis (i.e. the costs of two methods producing the same outcome) by Touchette and Rhoney (2000) showed that phenytoin was the preferred option in $97.3 \%$ of occasions: expected total treatment costs \$US5.39 vs 110.14 with fosphenytoin (Table 7). However, one-way sensitivity analysis demonstrated that the frequency and cost of treating an episode of purple glove syndrome could possibly affect the decision. A two-way sensitivity analysis was conducted with the cost and frequency of purple glove syndrome as variables. For fosphenytoin to be the preferred option the rate of purple glove syndrome with phenytoin had to exceed $1 \%$ and/or the cost of managing this adverse event had to exceed \$US10 000/episode (Touchette \& Rhoney 2000). The base case analysis was derived from a study that used reduced rates of administration of phenytoin and fosphenytoin, which biased the magnitude of the difference in adverse events seen with the intravenous administration rates of the two drugs (Coplin et al. 2002). The rate of purple glove syndrome with phenytoin treatment in this study is therefore likely to be lower than expected. O'Brien et al. reported an incidence of purple glove syndrome with phenytoin of up to 5.9\% (O'Brien et al. 1998). Thus it may be that fosphenytoin could be more costeffective when a higher incidence of adverse events, such as purple glove syndrome, with phenytoin is taken into account.

\section{Table 7 | Summary of economic studies involving intravenous fosphenytoin}

\begin{tabular}{|c|c|c|c|c|}
\hline $\begin{array}{l}\text { Level of } \\
\text { evidence }\end{array}$ & Analysis and outcome & Comparators & Study population & $\begin{array}{l}\text { Study } \\
\text { reference }\end{array}$ \\
\hline 2 & $\begin{array}{l}\text { Cost-minimization analysis from an RCT } \\
\text { Total treatment cost for base case of } \$ \text { US5.39 for PT vs. } \$ \text { US } 110.14 \\
\text { for FOS. PT was the preferred option for } 97.3 \% \text { of patients }\end{array}$ & FOS (iv) vs PT (iv) & $\begin{array}{l}\text { Base case from a randomized trial } \\
\text { ( } n=77 \text { PT; } n=202 \text { FOS) }\end{array}$ & $\begin{array}{l}\text { Touchette \& } \\
\text { Rhoney 2000; } \\
\text { Coplin et al. } \\
2002\end{array}$ \\
\hline 2 & $\begin{array}{l}\text { Cost-effectiveness based on rates of } A E \text { and time to safe discharge from } \\
\text { ED from an RCT } \\
\text { Treatment cost per patient was } \$ U S 2.83,21.16 \text {, and } 175.19 \text { for oral PT, } \\
\text { iv PT, and iv FOS, respectively } \\
\text { Cost-effectiveness ratios were } \$ \text { US3.90/h of ED time saved for oral PT } \\
\text { vs iv PT and } \$ \text { US387.27/h of ED time saved for iv FOS vs iv PT }\end{array}$ & FOS (iv) vs PT (iv) & $\begin{array}{l}\text { Outcomes and costs from an RCT. } \\
\text { ( } n=16 \text { oral PT; } n=14 \text { iv PT; } n=15 \text { iv } \\
\text { FOS) }\end{array}$ & $\begin{array}{l}\text { Rudis et al. } \\
2004 \\
\text { Swadron et al. } \\
2004\end{array}$ \\
\hline 2 & $\begin{array}{l}\text { Drug acquisition cost and estimated cost to manage AEs within the ED } \\
\text { Total ED drug-related AE costs per patient were \$US536.86 for PT } \\
\text { compared with } \$ \text { US66.68 for FOS. Subtracting drug acquisition costs } \\
\text { results in a net saving of } \$ \text { US386.89 with FOS }\end{array}$ & FOS (iv) vs PT (iv) & Not SE patients, $n=39$ FOS; $n=13$ PT & $\begin{array}{l}\text { Marchetti et } \\
\text { al. } 1996\end{array}$ \\
\hline 2 & $\begin{array}{l}\text { Cost estimation and cost-effectiveness } \\
\text { For loading doses average cost-effectiveness ratio of iv PT alone } \\
\text { (\$US225) was higher than iv FOS (\$US130) } \\
\text { Incremental cost-effectiveness ratio was } \$ \text { US97 to replace PT } \\
\text { loading doses with FOS }\end{array}$ & FOS (iv) vs PT (iv) & $\begin{array}{l}\text { Study based on questionnaire given to } \\
\text { nurses to determine incidence and } \\
\text { outcomes with AEs with PT and FOS }\end{array}$ & $\begin{array}{l}\text { Armstrong et } \\
\text { al. } 1999\end{array}$ \\
\hline
\end{tabular}


Finally, cost data were used with effectiveness data from a questionnaire (covering drug administration, frequency of adverse events and their management) used with 33 nurses to determine cost-effectiveness with fosphenytoin (Armstrong et al. 1999). The study showed that the average expected cost of phenytoin alone (\$US58) was less than when $50 \%$ of patients were treated with fosphenytoin and 50\% with phenytoin (\$US94), or when fosphenytoin was used alone (\$US130). However, the cost-effectiveness ratio is a more useful measure, as it reflects the cost to achieve the loading dose of the drug without complication. Thus, the average cost-effectiveness ratios were \$US225 for phenytoin alone, \$US149 for the 50 : 50 option and $\$$ US130 for fosphenytoin alone. The incremental costeffectiveness ratio was approximately $\$$ US97 to replace phenytoin loading doses with fosphenytoin, which was accepted as a reasonable increase in cost to achieve a reduction in adverse events (Armstrong et al. 1999).

\section{Resource utilization}

Rapid control of seizures in SE is necessary to limit the potentially damaging neurologic morbidity and the resulting costs in treating complications that can occur if treatment is delayed. The advantages of fosphenytoin compared with phenytoin include a faster rate of administration and a reduced potential for adverse events, particularly venous irritation and cardiac toxicity. Monitoring potential adverse events is essential when using intravenous phenytoin, and typically blood pressure, respiration, and continuous electrocardiogram (ECG) are observed. As the risk of hypotension exists with intravenous fosphenytoin administration at the recommended rate of administration ( $\leq 150 \mathrm{mg}$ phenytoin equivalent per minute) continuous monitoring of these parameters is also essential. Therefore cost implications associated with the use of monitoring equipment are present irrespective of the choice between intravenous phenytoin or fosphenytoin for treating SE.

Since the infusion rate for fosphenytoin can be up to three times faster than that with phenytoin this may save time in the ED and reduce resource use. There is also a potential saving of resource use through the avoidance of adverse events, and it has been estimated that the use of intravenous fosphenytoin results in an incremental cost-effectiveness of \$US97 per adverse event avoided (Armstrong et al. 1999). Although there has been a focus on the large difference in cost between the two drugs this must be weighed against the medical costs and resources necessary to treat complications resulting from intravenous phenytoin or sequelae of inadequately controlled prolonged SE.

\section{Patient group/population}

Most patients with SE are eligible for treatment with intravenous fosphenytoin. There is limited evidence that fosphenytoin may be a more appropriate choice in selective populations. First, large vein access for the administration of intravenous phenytoin can be problematic in children, the elderly, or other SE patients with restricted venous access. In addition, the formulation can be painful and there is a risk of extravasation. Therefore, the use of intravenous fosphenytoin via peripheral vein access may offer advantages over phenytoin, although there is currently no published evidence in these specific groups. Second, in resourcepoor countries fosphenytoin may offer both clinical and practical advantages compared with intravenous phenytoin. For example, intravenous phenytoin must be infused slowly when treating SE, but this is not always possible in some basic health facilities (Ogutu et al. 2003). Therefore, fosphenytoin may be a useful option in these circumstances, although this must be weighed against the impact of its higher acquisition cost in countries with limited healthcare resources.

There is limited evidence from case studies (level 4 evidence) indicating that parenteral fosphenytoin may be useful in seizure management in premature or extremely low-birthweight infants (Kriel \& Cifuentes 2001). However, close monitoring of free phenytoin levels is advised, as there may be some variability in therapeutic phenytoin plasma concentrations. For example, unexpected subtherapeutic levels of phenytoin following intravenous fosphenytoin were observed in a 3-year-old boy (Koul $\&$ Deleu 2002) and one infant aged $\leq 1$ year (Takeoka et al. 1998). The elimination half-life of intravenous fosphenytoin was not significantly different between neonates (<29 days), infants ( 2 days to $<2$ years), children ( 2 to $<12$ years), and adolescents ( 12 to $<17$ years). In addition, the elimination half-life in children (7.1 min; 5-10 years) is not significantly different to that in adults (7.9 $\mathrm{min}$; $16-75$ years) (Fischer et al. 2003). Therefore, as the rate of conversion of fosphenytoin to phenytoin remains consistent with age it would appear that the subtherapeutic levels of phenytoin seen in some neonates and infants (Takeoka et al. 1998; Koul \& Deleu 2002) may be attributable to high clearance of phenytoin (reviewed in Fischer et al. 2003). Thus, it may be prudent to monitor therapeutic blood levels of phenytoin carefully following fosphenytoin administration in these groups.

\section{Dosage, administration, and formulations}

Fosphenytoin (5,5-diphenyl-3-[(phosphonooxy)methyl]-2,4imidazolidinedione disodium salt; Cereby ${ }^{\circledR}$; fosphenytoin sodium injection) is a prodrug of phenytoin and accordingly, its anticonvulsant effects are attributable to phenytoin. It is supplied in vials containing $75 \mathrm{mg} / \mathrm{mL}$ fosphenytoin sodium equivalent to $50 \mathrm{mg} / \mathrm{mL}$ phenytoin sodium after administration. This formulation is supplied as a ready-mixed solution in water for injection and Tromethamine (tris) buffer adjusted to $\mathrm{pH}$ 8.6-9 with either hydrochloric acid or sodium hydroxide.

The loading dose of fosphenytoin for treating SE is 15-20 mg phenytoin equivalent per kilogram administered at $100-150 \mathrm{mg}$ phenytoin equivalent per minute. Fosphenytoin administered intramuscularly should not be used in the treatment of SE because therapeutic phenytoin concentrations may not be reached as quickly as with intravenous administration.

Fosphenytoin is indicated for short-term parenteral administration when other means of phenytoin administration are unavailable, inappropriate, or deemed less advantageous. The safety and effectiveness of fosphenytoin in this use has not been systematically evaluated for more than 5 days. Fosphenytoin can be used for the control of GCSE and the prevention and treatment of seizures occurring during neurosurgery. It can also be substituted, short term, for oral phenytoin (Cerebyx 2002). 


\section{Clinical value}

Fosphenytoin retains the pharmacologic properties of phenytoin with the advantage of an improved adverse event profile. Two factors that influence outcome following therapy for SE are good drug tolerability and rapid administration, and the available evidence suggests that fosphenytoin is superior to phenytoin in both instances.

Evidence from available studies in SE patients shows that fosphenytoin is at least as effective as phenytoin both in terms of speed of seizure resolution and the number of patients that respond in the treatment of the condition.

There is moderate evidence that therapeutic phenytoin blood levels after intravenous fosphenytoin administration are achieved at least at a similar rate compared with intravenous phenytoin.

There is also evidence confirming that the risk of venous adverse events with fosphenytoin is lower than with phenytoin, when administered at the recommended rate. Blood pressure and cardiac monitoring should be maintained with fosphenytoin, particularly during and immediately after the infusion, because hypotension and arrhythmias can occur with the active principle (phenytoin).

There are patient populations for whom treatment with phenytoin may not be appropriate, in particular those with poor peripheral vascular access (e.g. children, the elderly, and intravenous drug abusers). Fosphenytoin may therefore be a preferred option in these patients although there is very limited evidence to confirm this benefit.

Clearly the higher acquisition cost of fosphenytoin compared with phenytoin is an issue. Nevertheless, there is evidence that when fosphenytoin is administered as recommended the incidence of adverse events is lower than with phenytoin, thereby avoiding costly management and treatment of these events, which would influence the cost-effectiveness of fosphenytoin.

Thus, current evidence suggests that fosphenytoin is a valuable drug for the rapid treatment and control of SE.

\section{References}

ACEP Clinical Policies Committee. Clinical policy: critical issues in the evaluation and management of adult patients presenting to the emergency department with seizures. Ann Emerg Med. 2004;43:605-625.

Allen FH Jr, Runge JW, Legarda S, et al. Safety, tolerance, and pharmacokinetics of intravenous fosphenytoin (Cerebyx) in status epilepticus. Epilepsia. 1995;36(Suppl. 4):90.

Andrews CO, Turnbull TL, Paloucek FP, et al. Safety and pharmacokinetics of fosphenytoin following intravenous loading dose administration. Pharmacotherapy. 1994;14:367.

Appleton R, Choonara I, Martland T, et al. The treatment of convulsive status epilepticus in children. Arch Dis Child. 2000;83:415-419.

Armstrong EP, Sauer KA, Downey MJ. Phenytoin and fosphenytoin: a model of cost and clinical outcomes. Pharmacotherapy. 1999;19:844-853.

Baron B, Hankin S, Knapp L. Incidence of complications with intravenous administration of fosphenytoin (Cerebyx) compared with Dilantin. Neurology. 1995;45(Suppl. 4):A248.

Boucher BA, Feler CA, Dean JC, et al. The safety, tolerability, and pharmacokinetics of fosphenytoin after intramuscular and intravenous administration in neurosurgery patients. Pharmacotherapy. 1996;16:638-645.
Browne TR. Fosphenytoin (Cerebyx). Clin Neuropharmacol. 1997;20:1-12.

Cereby $x^{\circledR}$. Product information. 2002 Eisai Inc., Teaneck, NJ, USA. URL available at http://www.eisai.com/package_inserts/Cerebyx\%20Package\%20Insert.pdf (last accessed January 5, 2005).

Claassen J, Hirsch LJ, Mayer SA. Treatment of status epilepticus: a survey of neurologists. J Neurol Sci. 2003;211:37-41.

Coplin WM, Rhoney DH, Rebuck JA, et al. Randomized evaluation of adverse events and length-of-stay with routine emergency department use of phenytoin or fosphenytoin. Neurol Res. 2002;24:842-848.

DeLorenzo RJ, Garnett LK, Towne AR, et al. Comparison of status epilepticus with prolonged seizure episodes lasting from 10 to 29 minutes. Epilepsia. 1999;40:164-169.

DeLorenzo RJ, Pellock JM, Towne AR, et al. Epidemiology of status epilepticus. J Clin Neurophysiol. 1995;12:316-325.

Fierro LS, Savulich DH, Benezra DA. Safety of fosphenytoin sodium. Am J Health-Syst Pharm. 1996;53:2707-2712.

Fischer JH, Patel TV, Fischer PA. Fosphenytoin. Clin Pharmacokinet. 2003;42:33-58.

Holmes GL, Riviello JJ. Consequence and treatment of refractory status epilepticus. Int Pediatr. 1999;14:208-212.

Jamerson BD, Dukes GE, Brouwer KL, et al. Venous irritation related to intravenous administration of phenytoin versus fosphenytoin. Pharmacotherapy. 1994;14:47-52.

Jobst BC, Holmes GL. Prescribing antiepileptic drugs. CNS Drugs. 2004;18:617-628.

Koul R, Deleu D. Subtherapeutic free phenytoin levels following fosphenytoin therapy in status epilepticus. Neurology. 2002;58:147-148.

Kriel RL, Cifuentes RF. Fosphenytoin in infants of extremely low birth weight. Pediatr Neurol. 2001;24:219-221.

Logroscino G, Hesdorfer DC, Cascino GD, et al. Long-term mortality after a first episode of status epilepticus. Neurology. 2002;58:537-541.

Lowenstein DH, Alldredge BK. Status epilepticus. N Engl J Med. 1998;338:970-976.

Manno EM. New management strategies in the treatment of status epilepticus. Mayo Clin Proc. 2003;78:508-518.

Marchetti A, Magar R, Fischer J, et al. A pharmacoeconomic evaluation of intravenous fosphenytoin (Cerebyx $\AA$ ) versus intravenous phenytoin (Dilantin $₫$ ) in hospital emergency departments. Clin Ther. 1996;18:953-966.

O'Brien TJ, Cascino GD, So EL. Incidence and clinical consequence of the purple glove syndrome in patients receiving intravenous phenytoin. Neurology. 1998;51:1034-1039.

Ogutu BR, Newton CRJC, Muchohi SN, et al. Pharmacokinetics and clinical effects of phenytoin and fosphenytoin in children with severe malaria and status epilepticus. Br J Clin Pharm. 2003;56:112-119.

Rosenow F, Arzimanoglou A, Baulac M. Recent developments in treatment of status epilepticus: a review. Epileptic Disord. 2002;4(Suppl. 2):S1-11.

Rudis MI, Touchette DR, Swadron SP, et al. Cost-effectiveness of oral phenytoin, intravenous phenytoin, and intravenous fosphenytoin in the emergency department. Ann Emerg Med. 2004;43:386-397.

Rüeegg SJ, Dichter MA. Diagnosis and treatment of nonconvulsive status epilepticus in an intensive care unit setting. Curr Treatment Options Neurol. 2003;5:93-110.

Runge JW, Sloan WP, Turnbull, et al. Intravenous fosphenytoin loading for emergent seizure control. Ann Emerg Med. 1995;25:139.

Scott RC, Surtees RAH, Neville BGR. Status epilepticus: pathophysiology, epidemiology, and outcomes. Arch Dis Child. 1998;79:73-77.

Shorvon S. The management of status epilepticus. J Neurol Neurosurg Psychiatry. 2001;70(Suppl. II):ii22-ii27.

Sirven JI, Waterhouse E. Management of status epilepticus. Am Fam Physician. 2003;68:469-476. 
Swadron SP, Rudis MI, Azimian K, et al. A comparison of phenytoin-loading techniques in the emergency department. Acad Emerg Med. 2004;11:244-252.

Swaminathan S, Sawhney IMS, Jain S, et al. Profile of status epilepticus: a prospective study. Neurol India. 1998;46:279-283.

Takeoka M, Krishnamoorthy KS, Soman TB, et al. Fosphenytoin in infants. J Child Neurol. 1998;13:537-540.

Touchette DR, Rhoney DH. Cost-minimization analysis of phenytoin and fosphenytoin in the emergency department. Pharmacotherapy. 2000;20:908-916.

Towne AR, Pellock JM, Ko D, et al. Determinants of mortality in status epilepticus. Epilepsia. 1994;35:27-34.
Treiman DM. Convulsive status epilepticus. Curr Treatment Options Neurol. 1999;1:359-369.

Treiman DM, Meyers PD, Walton NY, et al. A comparison of four treatments for generalized convulsive status epilepticus. N Engl J Med. 1998;339:792-798.

Weinstein MC, Siegel JE, Gold MR, et al. Recommendations of the panel on cost-effectiveness in health and medicine. JAMA. 1996;276:1253-1258.

Correspondence: Andrew Thomson, Core Medical Publishing, Mere House, Brook Street, Knutsford, Cheshire WA16 8GP, UK or at editor@coreevidence.com 